\title{
Improving vocational interest assessments: data complexity levels are important for social and enterprising areas
}

\author{
Yonca Toker ${ }^{1}$, Aysu Gökalp ${ }^{1}$, Yalçın Açıkgöz ${ }^{2}$ \\ ${ }^{1}$ Department of Psychology, Middle East Technical University, Turkey, ${ }^{2}$ Department of \\ Psychology, Appalachian State University, USA.
}

\begin{abstract}
Vocational interest assessments are open to imporvements to achieve higher predictive validities. One recent approach in developing interests assessments has been to incorporate more complex vocational activities in items (Toker \& Ackerman, 2012). In this study we developed the Vertical Social Interests Scale (VSIS)-Data Complexity Levels to be used together with the VSIS-People Complexity Levels (Açıkgöz \& Toker, 2019) to assess interests in increasingly complex activities related to the social and enterprising vocational areas. Data complexity levels in the Dictionary of Occupational Titles which are present in the work activities of social/enterprising occupations identified in the $O * N E T$ were incorporated in developing scale items. The new measure was evaluated on a sample of 238 college students., yielding a 3-factor structure reflecting high-, moderate-, and low-complexity work activities. The moderateand-high complexity factor composites had expected associations with other interest and self-efficacy measures together with several vocational criteria, adding support to the developing literature on the importance of measuring interests for increasingly complex activities.
\end{abstract}

Keywords: Vocational interests; assessment; occupational complexity; social interests; enterprising interests. 


\section{Introduction}

An important part of transitioning from high school to a college major and a career is making sound decisions as to one's vocational area. Counselling provided based on vocational interest assessments take most of the credit in such decisions. Nevertheless, such assessments have been criticized to lack validity in predicting vocational outcomes (e.g., Nauta, 2010). Incorporating occupations' increasingly complex activities into vocational interest assessments have proven more useful than traditional interest assessments in predicting vocational criteria at the college and work-life levels (Açıkgöz \& Toker, 2019; Toker, 2018; Toker \& Ackerman, 2012; Toker \& Gültaş, 2019). One of these assessments focused on targeting more complex activities in the occupations under Holland's (1997) Realistic and Investigative work environments (Toker \& Ackerman, 2012) whereas the other assessment developed so far focused on Social and Enterprising work environments. The latter only measures interests towards interacting with people (Açıkgöz \& Toker, 2019). Nevertheless Social and Enterprising occupations also vary in their complexity levels in terms of dealing with "data". The focus of the present study was developing an interest assessment for these areas that incorporated increasingly complex activities to do with interacting with data.

The Dictionary of Occupational Titles (DOT; U.S. Department of Labor, 1991) was consulted to locate the occupations that differed based on the $4^{\text {th }}$ digit code that reflects varying levels of complexity with interacting with data from the lowest level of "comparing" to the highest level of "synthesizing/generating". A total of 125 occupations (56 highcomplexity, 60 moderate-complexity, 9 low-complexity occupations) were selected and analyzed based on their work activities and tasks as described in $\mathrm{O}$ *NET. Interviews were conducted with 39 employees, including lawyers, executives, business people, academicians (high-complexity occupations), nurses, sales representatives, executive assistants, police officers (moderate-complexity occupations), and chefs, baristas, and cashiers (lowcomplexity occupations), asking them for the most frequent tasks involving dealing with data. Information gathered from $\mathrm{O} * \mathrm{NET}$ and the interviews were used in item generation.

A 33-item measure, named the Vertical Social Interests Scale - Data Complexity Levels (VSIS_DCL), was developed to reflect varying levels of complexity in social and enterprising areas. A validation study was conducted on a college student sample. As items were generated to reflect three complexity levels, the first hypothesis was:

Hypothesis 1. The VSIS_DCL will have a 3-factor structure, reflecting low-, moderate-, and high DOT data complexity levels.

The VSIS_DCL was developed for the social and enterprising areas, thus:

Hypothesis 2. The VSIS_DCL factors will have moderate associations with social, enterprising, and investigative interests and self-efficacies. 
The most important criteria used in the validation of interest assessments have been area satisfaction and persistence, albeit with small effect sizes (e.g., Nauta, 2010; Nye et al., 2012; Spokane et al., 2000; Tracey and Robbins, 2006; Van Iddekinge et al., 2011). Assessing interests towards more complex tasks have added incremental variance to these traditional assessments (e.g. Ackerman \& Toker, 2012), thus:

Hypothesis 3: The VSIS_DCL high- and moderate-complexity factors will add incremental variance over the traditional assessments in predicting relevant vocational criteria such as satisfaction and persistence.

\section{Method}

\subsection{Participants and Procedure}

Undergraduate college students from a technical university in Ankara, Turkey participated in the current study. Majority of the students participated in return for course credit upon receiving IRB approval. The sample consisted of 238 (74.5\% women) students. One person was 42 and the remaining participants' ages ranged from 18 to 28 (with $36.1 \%$ at the age of 21). Of the participants $68.9 \%$ were enrolled in Administrative, Economical, and Social Sciences (AESS) (45.4\% psychology, 9.2\% education sciences, 7.1\% sociology/philosophy, $1.7 \%$ economics and $5.5 \%$ political sciences, public administration and business administration) and 30.6\% were enrolled in STEM majors (21.8\% engineering, $8 \%$ biology, molecular biology, physics and chemistry and $0.8 \%$ statistics) and there was one participant from the faculty of law. Grade distribution was $6.3 \%$ freshmen, $31.9 \%$ junior, $34.5 \%$ sophomore, $17.2 \%$ senior, and $6.3 \%$ in their fifth, sixth or seventh years.

\subsection{Measures}

\subsubsection{Vertical Social Interests Scale_Data Complexity Levels (VSIS_DCL)}

The 33-item measure was rated on a 6-point scale from "not enjoyable at all" to "very enjoyable". According to DOT levels, there were 2 comparing, 4 copying (6 lowcomplexity), 5 compiling, 5 analyzing (10 moderate-complexity), 4 planning/coordinating, 8 synthesizing, and 5 generating (17 high-complexity) items. Two example items were "Analyzing various ideas, propositions, methods, and perspectives related to the AESS areas, with their pros/cons and strong/weak sides" (analyzing) and "Going over verbal information, combining them in various ways, and proposing ideas with a new perspective (For instance, an attorney interpreting the legislations in a way that would vindicate the client; or a teacher preparing an attractive class activity)" (generating item). 


\subsubsection{Vertical Social Interests Scale_People Complexity Levels (VSIS_PCL)}

The 36-item scale (Açıkgöz \& Toker, 2019) was rated on a 6-point scale ranging from "not enjoyable at all" to "very enjoyable". The scale has four factors of serving (low-complexity, 10 items), supervision (moderate-complexity, 7 items), leading (high-complexity, 11 items), and communication (moderate- and high-complexity, 8 items) with internal consistencies varying from .81 to .92 in college samples.

\subsubsection{Self-Directed Search}

Holland's (1997) RIASEC theme interests and self-efficacies were measured with a total of 120 items, adapted to Turkish by Balkış (2004) with internal consistency reliabilities from .74 to .88 . Items were rated on a 6-point scale.

\subsubsection{Major Satisfaction}

Students' satisfaction with their major and their experiences (e.g. courses enrolled, intellectual stimulation) were assessed with 7-items rated on a 6-point scale ranging from "does not describe me at all" to "describes me very well" (Lent et al., 2005), adapted to Turkish by Toker and Gültaş (2019) with an internal consistency of .93.

\subsubsection{Intentions to further Pursue the Academic Area}

The 10-item scale (Toker, 2010) was used to assess participants' intentions to graduate from and further pursue the area they are enrolled in with a graduate degree and a career. Internal consistency was .91 (Toker \& Gültaş, 2019).

\subsubsection{Interest towards Research Assistant (RA) Activities}

A 9-item measure was developed for this study to assess interests towards increasingly complex RA tasks on a 6-point scale. An example item is Analyzing how a scientific article's results would contribute to the topic.

\subsubsection{Social activities}

Participants were asked to indicate the social/organizing-related activities they took part in during their college life. Amongst these activities were participating in debates, being a member of university clubs, being the president of a club/society in college, active participation in organizing an event, being the spokesperson of a group, writing blogs, periodically writing in non-academic journals. A total social activity score was computed based on the number of activities participants selected. 


\section{Results}

A pilot analyses with 156 students yielded a 3-factor solution based on Principal Axis Factoring with oblique rotation. A total of $45.7 \%$ of variance was explained before rotation, with $34.8 \%, 6.4 \%$, and $4.5 \%$ of variance explained by the high-, low-, and moderatecomplexity factors, respectively. Items mostly loaded on the complexity levels they were designed to represent, supporting Hypothesis 1. Three items with cross-loadings, ambiguous content or low-loading were removed, leaving 30 items. Data on these 30 items were gathered from the remaining participants. Internal consistencies in the entire dataset were .93 (17 items), .91 ( 8 items), and .73 (5 items) for the high-, moderate-, and low-complexity factors, respectively.

VSIS_DCL factor means were statistically significantly higher in the AESS sample $(N=161)$ than in the sample of students enrolled in other majors $(N=77)$. Specifically, interests of AESS students towards activities with verbal data were higher for high-complexity activities $\left(M_{\text {AESS }}=4.68, M_{\text {Other }}=3.87, p<.001\right.$, Hedges' $\left.g=1.02\right)$, moderate-complexity activities $\left(M_{\text {AESS }}=4.78, M_{\text {Other }}=3.73, p<.001\right.$, Hedges' $\left.g=1.15\right)$, and low-complexity activities $\left(M_{\text {AESS }}\right.$ $=3.31, M_{\text {Other }}=2.85, p=.003$, Hedges' $g=.48$ ). Factors of the VSIS_PCL did not differ across the samples. Holland social interests $\left(M_{\text {AESS }}=4.90, M_{\text {Other }}=3.93, p<.001\right.$, Hedges' $g$ $=1.20)$ and social self-efficacy $\left(M_{\text {AESS }}=4.62, M_{\text {Other }}=4.03, p<.001\right.$, Hedges' $\left.g=0.67\right)$ were higher in the AESS sample, whereas enterprising interests and self-efficacy did not differ.

Theoretically, construct validity evidence based on associations between vocational interests and self-efficacies needs to be analyzed within the entire sample of participants. Accordingly, VSIS_DCL high- and moderate-complexity scales were correlated strongly with each other $(r=.82)$, but had smaller correlations with the low-complexity scale $(r=.34, r=.37)$. The people high-complexity leading and communication factors were also correlated strongly $(r$ $=.54$ ). All three factors of the VSIS_DCL correlated with social self-efficacy from .24 to .44 and with social interests from .39 to .51 . The high-complexity factor had significant moderate correlations with enterprising self-efficacy and interests $(r=.32, r=.26)$, and the moderatecomplexity factor had a small significant correlation with enterprising self-efficacy $(r=.19)$. The low-complexity factor did not correlate with enterprising self-efficacy or interests. Realistic and conventional themes were discriminated from the VSIS_DCL high- and moderate-complexity interests with small associations ( $|r| .00$ to .22$)$. The low-complexity factor, though, was associated with conventional self-efficacy $(r=.19)$ and interests $(r=.37)$. Artistic interests and self-efficacy were found to have small-to-moderate associations with all three complexity levels of VSIS_DCL ( $r$ 's .16 to .33).

Associations across the investigative theme and VSIS_DCL factors were analyzed within the AESS sample as investigative interests can be discipline-specific. AESS students with higher 
investigative interests/self-efficacy also reported higher interests on high- and moderatecomplexity VSIS_DCL ( $r$ 's .25 to .48). All-in-all, Hypothesis 2 found support.

Hierarchical regression analyses were conducted to investigate the incremental variance VSIS_DCL scores have over the traditional Holland assessments. Satisfaction with academic major, a combined score of intentions to pursue an undergraduate degree, a graduate degree and a career, interests towards RA activities, and participation in social activities were predicted from a composite of social interests and self-efficacy, a composite of enterprising interests and self-efficacy, and a composite of investigative interests and self-efficacy in the first step, and a composite of the VSIS_PCL leading, supervising, and communication factors, and a composite of the VSIS_DCL high- and moderate-complexity factors in the second step.

Results (see Table 1) indicated that intention to pursue an AESS area was predicted by social interests/efficacy $(\beta=.28, p<.001)$ and VSIS_DCL $(\beta=.47, p<.001)$. Satisfaction with academic major was predicted by social interests/efficacy $(\beta=.29, p<.001)$ and VSIS_DCL $(\beta=.36, p<.001)$. Interests towards RA activities were predicted by VSIS_PCL $(\beta=.31, p$ $=.003)$ and VSIS_DCL $(\beta=.34, p<.001)$, and inversely by enterprising interests/efficacy ( $\beta=-.27, p=.011)$. Thus, Hypothesis 3 found support. Social activity participation was predicted only by enterprising $(\beta=.24, p=.006)$ and investigative interests/efficacy $(\beta=.22$, $p=.007)$ in the first step.

\section{Discussion}

This study has provided initial evidence for the factorial structure, construct, and concurrent criterion-related validity of the VSIS_DCL. Items written to reflect the DOT complexity levels factored together within their complexity levels. Only three items were dropped from the measure. The high- and moderate-complexity factors were more highly correlated with each other than their associations with the low-complexity factor; a finding consistent with the VSIS_PCL (Açıkgöz \& Toker, 2019) and the STEM Complexity Measure (Toker \& Ackerman, 2012; Toker \& Gültaş, 2019).

AESS majors indicated higher interests on the VSIS_DCL factors and on social interests as compared to the small sample of other majors. Consistent with the findings of Açıkgöz and Toker (2019) enterprising interests and self-efficacy were no different across the samples. Major differences were not observed for the VSIS_PCL factors either, rendering the VSIS_DCL potentially more useful. 
Table 1. regression analyses

\begin{tabular}{|c|c|c|c|c|}
\hline & $\begin{array}{l}\text { Intentions to } \\
\text { Pursue AESS }\end{array}$ & $\begin{array}{c}\text { Satisfaction with } \\
\text { AESS major }\end{array}$ & $\begin{array}{l}\text { Interests for } \\
\text { RA activities }\end{array}$ & $\begin{array}{c}\text { Social } \\
\text { participation }\end{array}$ \\
\hline \multicolumn{5}{|l|}{ Block 1} \\
\hline Social interest \& SE & $.40^{* * *}$ & $.37 * * *$ & $.18^{*}$ & .03 \\
\hline $\begin{array}{l}\text { Enterprising interest } \\
\& \mathrm{SE}\end{array}$ & -.12 & -.05 & -.09 & $.24 * *$ \\
\hline $\begin{array}{l}\text { Investigative interest } \\
\& \mathrm{SE}\end{array}$ & .07 & .05 & $.20^{*}$ & $.22 * *$ \\
\hline$F(d f)$ & $8.87(3,157)^{* * *}$ & $8.03(3,157)^{* * *}$ & $4.35(3,157)$ & $8.36(3,140)^{* * *}$ \\
\hline $\mathrm{R}^{2}$ & $14.5 \%$ & $13.3 \%$ & $7.7 \%$ & $15.2 \%$ \\
\hline \multicolumn{5}{|l|}{ Block 2} \\
\hline Social interest \& SE & $.28 * * *$ & $.29 * * *$ & .09 & .00 \\
\hline $\begin{array}{l}\text { Enterprising interest } \\
\text { \& SE }\end{array}$ & -.20 & -.03 & $-.27 *$ & .14 \\
\hline $\begin{array}{l}\text { Investigative interest } \\
\& \mathrm{SE}\end{array}$ & -.15 & -.10 & .04 & .17 \\
\hline $\begin{array}{l}\text { VSIS_PCL H \& M } \\
\text { comp }\end{array}$ & .16 & .01 & $.31 * *$ & .17 \\
\hline $\begin{array}{l}\text { VSIS_DCL H \& M } \\
\text { comp }\end{array}$ & $.47 * * *$ & $.36 * * *$ & $.34 * * *$ & .10 \\
\hline$F(d f)$ change & $20.36(2,155)^{* * *}$ & $9.61(2,155)^{* * *}$ & $13.09(2,155)^{* * *}$ & $2.01(2,138)$ \\
\hline $\mathrm{R}^{2}$ change & $17.8 \%$ & $9.6 \%$ & $13.3 \%$ & $2.4 \%$ \\
\hline
\end{tabular}

Notes. SE: self-efficacy, VSIS: Vertical Social Interests Scale, DCL: Data Complexity Levels; PCL: People Complexity Levels; H: High-complexity, M: Moderate-complexity. Values in cells are Beta coefficients, unless otherwise indicated. $* \mathrm{p}<.05, * * \mathrm{p}<.01, * * * \mathrm{p}<.001$.

Support for the construct validity of the VSIS_DCL came from Holland's social interests and self-efficacy correlating with all factors, enterprising interests and efficacy correlating with the high-complexity factor and also the investigative theme correlating with the high- and moderate-complexity factor in the AESS sample. Significant correlations were also observed 
with VSIS_DCL factors and artistic interests and self-efficacy. This finding could be attributed to the artistic scales including items related to reading and writing literature.

VSIS_DCL appears to be a useful measure for AESS areas as indicated by the different means on factors and different correlations between factors scores and vocational criteria across the AESS and other majors. Regression analyses results showed that VSIS_DCL highand moderate-complexity factors were more predictive of intentions to further pursue an AESS area and satisfaction with being in an AESS area as compared to the VSIS_PCL or the Holland measures. Interests towards the activities that RAs engage in frequently were predicted by both complexity measures indicating that having an interest towards both complex data processing and handling people are important in the more complex work domains such the one of RAs. Finally, participating in social and organizing activities was predicted by enterprising interests in the absence of the complexity measures. Another important finding is that enterprising interests and self-efficacy do not predict more data driven pursuits such as intending to study further, being satisfied with the academic studies, or RA tasks. Actually enterprising measures' composite was an inverse predictor of interests towards RA tasks.

All-in-all, this study provided initial support for the construct and predictive validity of VSIS_DCL. Another data collection phase is underway for studying the measure's validity in graduate student and employed samples.

\section{Acknowledgements}

This work has been funded by The Scientific and Technological Research Council of Turkey TÜBİTAK Project No: 117K364

\section{References}

Açıkgöz, Y., \& Toker, Y. (2019). Integrating occupational complexity levels to interest assessments in social and enterprising areas: Development of the Vertical Social Interest Scale. Journal of Career Assessment, 27(1), 61-77. doi: 10.1177/1069072717748633

Balkış, M. (1994). An adaptation study of the self-directed search in Turkish Culture. Eurasian Journal of Educational Research, 17(3), 54-63.

Holland, J. L. (1997). Making Vocational Choices: A Theory of Vocational Personalities and Work Environments (3rd Ed.). Odessa, FL: Psychological Assessment Resources.

Lent, R. W., Singley, D., Sheu, H., Gainor, K. A., Brenner, B., Treistman, D., et al. (2005). Social cognitive predictors of domain and life satisfaction: Exploring the theoretical precursors of subjective well-being. Journal of Counseling Psychology, 52(3), 429-442. doi: 10.1037/0022-0167.52.3.429 
Nauta, M. M. (2010). The development, evolution, and status of Holland's theory of vocational personalities: Reflections and future directions for counseling psychology. Journal of Counseling Psychology, 57, 11-22. doi:10.1037/a0018213

Nye, C.D., Su, R., Rounds, J., \& Drasgow, F. (2012). Vocational interests and performance: A quantitative summary of over 60 years of research. Perspectives on Psychological Science, 7, 384-403. doi:10.1177/1745691612449021

Spokane, A. R., Meir, E. I., \& Catalano, M. (2000). Person-environment congruence and Holland's theory: A review and reconsideration. Journal of Vocational Behavior, 57(2), 137-187. doi: 10.1006/jvbe.2000.1771

Toker, Y. (2010). Cognitive and Non-cognitive Correlates of the Science-math Trait Complex: Searching for Personality Correlates and Revisiting Vocational Interests. Doctoral Dissertation: Atlanta: Georgia Institute of Technology.

Toker, Y. (2018, April). Vocational Interests toward complex occupations make a difference in STEM work life. Poster presentation at the Annual Conference of SIOP, Chicago, IL.

Toker, Y., \& Ackerman, P. L. (2012). Utilizing occupational complexity levels in vocational interest assessments:Assessing interests for STEM areas. Journal of Vocational Behavior, 80, 524-544. doi:10.1016/j.jvb.2011.09.001

Toker, Y., \& Gültaş, M. (2019). STEM Interest Complexity Inventory Sort Form with IRT and DIF applications. Journal of Career Assessment, 27(1), 78-96. doi: 10.1177/1069072717748645

Tracey, T. J. G., \& Robbins, S. B. (2006). The interest-major congruence and college success relation: A longitudinal study. Journal of Vocational Behavior, 69, 64-89. doi: 10.1016/j.jvb.2005.11.003

U.S. Department of Labor (1991). Dictionary of Occupational Titles (Revised 4th Edition): Employment and Training Administration.

Van Iddekinge, C. H., Putka, D. J., \& Campbell, J. P. (2011). Reconsidering vocational interests for personnel selection: The validity of an interest-based selection test in relation to job knowledge, job performance, and continuance intentions. Journal of Applied Psychology, 96(1), 13-33. doi: 10.1037/a0021193. 